\title{
EFFECTIVENESS OF VIRTUAL CLASS FOR PRE-PRIMARY LEVEL
}

\author{
Daman Bahadur Singh*
}

\begin{abstract}
The age of students studying in pre-primary class is 3 to 6 years. Their psychology and comprehension are different from those of adults. The curriculum and lesson plans developed for them differ from those in the adult age group. While teaching them, lessons should be planned by playing games and having fun. Physically present in the classroom and conducting teaching activitie will be more effective for the students of this boomer group. To maintain the discipline of the students of this age group in virtual class not so easy. It is difficult to give homework, teaching through different types of learning skills is not difficult, to follow them time is difficult, give necessary instructions is difficult, draw attention to reading and conduct whole-class activities through games and entertainment is also difficult to maintain in a virtual class. This study has clarified that the virtual class for this level of students is not suitable.
\end{abstract}

Keywords: Pre-primary, Effectiveness, virtual class, online teaching, teaching and learning

\section{Background of the Study}

A virtual classroom is an environment in which students and teachers interact with subject matter that needs to be studied with the help of computer, mobiles and other digital media without being physically present. Due to Covid 19 in Nepal, school and college education could not be conducted after being physically present in the classroom for about $9 / 10$ months. In such a situation, the practice of conducting virtual classes through the applications available online by the educational institutions of Nepal became widely practised.

Although such classes seem to be effective at the college level and the secondary level, it can be said that they have not been as effective at the pre-primary and primary levels. Very few people knew about virtual classes before the impact of COVID 19 in Nepal. At the same time, very few people were aware that teaching activities could be done through it, but it is well known that after the impact of Covid 19, its importance has increased and its use has become widespread.

It is no exaggeration to say that the training centres of Nepal and their affiliated manpower have become very accustomed to the virtual classroom. Assistant Professor of Saraswati Multiple Campus (Management Faculty: Statistics Department), Tribhuvan University,
Nepal. 


\section{The statement of the problem}

The management and operation of the infant classroom and lesson are more challenging, complex and sensitive as compared to classes of higher level. Children should be physically present in the classroom, understand the child psychology, prepare the classroom environment according to the wishes of the parents, and promote teaching and learning activities through recreational and games, which is not so easy to manage in a virtual class.

Even then, the schools were forced to conduct virtual classes as there was no possibility of conducting physical classes during the covid period, which was still challenging. On the one hand, the playful nature of the child, with child psychology at the centre, and how to conduct the classroom system and learning virtually through entertainment and games was no less challenging for the educational institution and teachers. Overall, the management of the infant class room and the transfer of knowledge and skills to the infant through virtual class is not less challenging.

\section{Review of Literature}

The epidemic of Covid 19 has ushered in a new era in the field of education not only in Nepal but all over the world. Along with the effect of Covid 19, applications such as zoom cloud, team, Google classroom etc. became widely used to manage the students' intensive reading through the online classroom with the help of mobile, laptop and computer. In this way, on the one hand, teachers and students get a golden opportunity to get acquainted with online technology.

Before this, most of the students and educators were ignorant about how the online class is conducted, how the teacher is useful to the students, how to take advantage of it, what kind of tools are needed for it and how it manage the teaching and learning skills. Now all the concerned parties are not ignorant about this issue.

There is no doubt that virtual class is more appropriate than physical class. Today is the age of technology. It is difficult to run our business without technology. That is to say, our daily work has become almost impossible without the use of technology. In the case of Nepal, Covid 19 hurt various sectors in which the education sector could not remain untouched.

It is a well-known fact that the tourism and education sectors have been affected the most by the covid. Various universities and educational institutions in Nepal have joined Nepal in the wave of online classes along with the global corona epidemic by preparing the necessary infrastructure and manpower. In a way, Nepal has also become capable.

\section{Method and Methodology}

Students studying in pre-primary class are usually in the age group of 3 to 6 years. Five schools of Kathmandu valley were selected for the study who have conducted virtual classe. Field Research method among different methods of qualitative research methods was selected and Obtained necessary informations by observing the classes directly. Among the five selected schools in the Kathmandu district, some of the students in the nursery, some in the UKG and some in the LKG class were found to be present 10-15 minutes later than the class operation time. 
It was found that the teacher spent a lot of time in various temptations to make them enthusiastic, reminding them to focus on reading. Even after the class was over, the student's attention was not focused on reading. Giving instructions to the same student over and over again did not prove to be very effective.

The role of the parent was not found to be what it should be during the class. The teacher was found to have spent a lot of time on the work during the class. Evaluating student achievement was also not very effective.

When asked questions, most of the students could not answer what they had learned. The kind of discipline that should be followed in the classroom was not found. Homework and it was found to be very difficult to remind the students. Due to the busyness of the parents' during the time of virtual class, it was very difficult for the student to give homework and make them cleared about it. Due to limited instruction and time home work was not done by most of the student.

\section{Analysis of Information}

Related Information was collected by the applied Field Research Method. Available Information was analyzed by Content Analysis. During analysis, It was found that most of the students were not connecting to the virtual class on time due to non-compliance At the same time, it takes a lot of time to focus the students on a virtual class, such as a physical classroom.

Similarly, the need for parental activism and monitoring depends on the virtual class operation time, due to the inability to give time due to their household chores. It was found that the extent to which the students understood the same subject matter in the same reading could not be evaluated properly.

Evaluation plays an important role. In immediately evaluating what has been taught and formulating a strategy accordingly for further classes. Students have to follow the prescribed discipline while sitting in the classroom but it seems to be difficult to maintain the discipline of the student in the virtual class like in the physical class due to various reasons. The verbal instruction of the teacher was found to be difficult to follow by the students due to the busyness of the parents.

Similarly, when giving homework, it was found that students could not maintain its proper direction and necessity. This is because it is not possible to give clear instructions in a copy, a book like in a physical class. At the same time, it was difficult to check whether they had done their homework or not because teacher did not create the compulsion to the students.

Based on the analysis of the information obtained one by one, it is clear that it is more difficult for infant level students to conduct teaching-learning activities through virtual class than physical class.

\section{Conclusion}

There is no debate to say virtual classes saving time and labour as well as help to make our teaching activity technology-friendly. But with resources like ours, it's not easy to make every one of our activities technology-friendly. In our country where 30 per cent of the population is 
still illiterate, to make technology known to all and to enable all citizens to use, it is like chewing a piece of iron. At the same time, it is not less challenging to find the necessary resources for technology in our economically poor country.

The rural areas of the country are still deprived of electricity. There is a situation of not being able to provide electricity for 24 hours in places where there is an electricity facility. Nepal cannot be technology-friendly without electricity facilities.

Nepal's universities and schools are in poor physical and technical condition. Lack of well manage classrooms is a long way from running technology-friendly classrooms on campuses and schools. Our country could not remain untouched when the epidemic of covid19 hit the world.

Due to this, various sectors were badly affected. When the universities and schools were closed for a long time, the students' studies were badly affected. With the launch of covid19, universities and schools of Nepal also launched online-based virtual classes. Even if there is no $100 \%$ attendance of students in such classes, in a country like ours, all the virtual classes should be considered satisfactory.

University reading activities were found to be more effective when conducted classes from a virtual class. Similarly, it can be considered as effective at the primary and secondary level in schools but not so effective at the pre-primary level. Studies have shown that virtual classes are not as comfortable as teachers used to be physically comfortable with infant classes.

Studies have shown that it is very difficult for students to maintain discipline, to evaluate the reading, to give homework and to check it. At the same time, it is clear from the study that it is equally difficult to draw the attention of students towards reading while virtual classes are being conducted.

Overall, the findings of this study suggest that infant classroom reading through virtual classes is not effective because of the poor economy as well as poor technology and technical manpower.

\section{References}

Chen, $\mathrm{J}$ and chang, C,(2006) using a computer in early childhood: teachers attitudes, skills and practices. Journal of early childhood,4(2) 169-188

Fedynich,L.v(2014). Teaching beyond the classroom walls. The prob. And cons of cyberlearning journal of instructional pedagogies, 13,1

Johnson, A.V. La Paro, J, and Crosby, D.A(2017), Early practicum experiences; Preservice early childhood students perceptions and sense of efficiency. Early childhood Education Journal45, 229-236

International journal of Research in Education and Science(IJRES), 2(1) 10-15

New Horizons 2012, key Statistics along online learning, Available from $<\mathrm{http}: / /$ computer training centres $\mathrm{com} /$ a dozen.eye opening-facts about e learning/> 
University of washington2013 online learning still plagued by uncertainty.Availiable from<OpBlog: Higher Ed Juction: HTTP//depta Washington.edu./Opbblog/2012/01 online learning-still- plagued-uncertainty/>

Yamagata-Lynch, LC 210 Activity systems analysis method: Understanding Complex learning environments, Springer, Newyork.

Alexander,s, 2001.'E learning developments and experiences" Education+Training, vol43 no.4/5, pp. $2040-248$

Fallon, G, 11" Exploring the virtual class room: what students knew and teachers should considered ") Meriot vol.7 no.4 pp439-451 